\title{
O ABORTO: UM RESGATE HISTÓRICO E OUTROS DADOS*
}

\section{ABORTION: A HISTORICAL RESCUE ANO OTHER DATA}

\author{
Néia Schor ${ }^{1}$ \\ Augusta T. de Alvarenga ${ }^{2}$
}

SCHOR, N.; ALVARENGA, A. T. O Aborto: Um Resgate Histórico e Outros Dados. Rev. Bras. Cresc. Dás. Hum., São Paulo, IV(2), 1994.

Resumo: Preocupados com os resultados recentes de pesquisas brasileiras sobre complicações após aborto, que indicam um crescente aumento no número desses eventos, além de registrarem uma alta incidência dos mesmos entre adolescentes, os autores propõem-se a analisar, neste trabalho, a prática do aborto sob uma Ética histórica, como um subsídio para se "repensar"a questão em futuras políticas de saúde no Brasil. Apresentam, para tanto, enfoques médicos, religiosos, políticos, legais, sociais, económicos e culturais sobre a questão do aborto, esposados pelos povos, desde as antigas civilizações, orientais e ocidentais, até os dias de hoje - todos eminentemente ditados por fatores econômicos, dependentes, obviamente, da facção que estivesse no poder em determinado contexto histórico. É apresentada, também, a legislação brasileira sobre o assunto.

Palavras-chave: aborto, ática histórica, saúde da mulher.

Summary: Concerned with data yelded by recent Brazilian pieces of research on complications after abortion, pointing out to an increasing growth in lhe occurrence of these events, besides their high incidence among adolescente, the authors intend to offer, in this paper, subsidies for a "rethinking" of the matter in futuro public health policies in Brazil. To do so, the authors present a historical approach, emphasizing the medical, religious, political, legal, social, economic and cultural views on the matter of abortion held by different civilizations (both eastern and western ones), since ancient times until nowadays - ali of them essentially economically oriented, obviously dependent on the faction holding the power at a given time. The Brazilian political legislation is also presented.

Key-words: abortion, historical view, women's health.

* Financiamento CNPq.

1 Enfermeira, Prof. DM. do Departamento de Saúde Materno-lnfantil da Faculdade de Saúde Pública da Universidade de São Paulo.

2 Socióloga, Prof. Dra. do Departamento de Saúde Materno-Infantil da Faculdade de Saúde Pública da Universidade de São Paulo.

End.: Av. Dr. Arnaldo 715 Sala 218, São Paulo - SP, CEP 0124 904 Fone: (011) 881.2451 ou 851.5233 ramais 2202 , 2203 e 2273 Fax: (011) 853.02411. 


\section{INTRODÇÃO}

Este trabalho tem como objetivo trazer à tona alguns dados históricos a respeito da questão da prática do aborto, analisando-a sob a ética das várias civilizações e religiões que ajudaram a compor a história do mundo.

O universo pesquisado foi de 2.588 mulheres carentes, apresentando complicações pós-aborto que procuraram o Hospital Municipal de Santo André no município da Grande São Paulo, no período de janeiro de 1978 a dezembro de 1982.

As conclusões mais marcantes foram a duplicação do número de abortos atendidos pelo serviço, na proporção de I aborto para 3,6 partas para 1 aborto para 1,8 Fartos, em 1978 e 1982 respectivamente e grande incidência do evento entre adolescentes. ${ }^{23}$

Dados como esses - concretos e expressivos - parecem levar a certo tipo de reflexão até mesmo óbvia: em que medida o aparente descaso por parte de autoridades médicas e governamentais em relação à questão da prática do aborto não está, de certa forma, contribuindo para o agravamento do problema?

Seguindo essa linha de raciocínio, estaríamos abrindo espaço para discussões em torno das políticas de: planejamento familiar; saúde reprodutiva; controle da natalidade; qualidade de assistência à mulher; qualidade de vida da população e, por que não dizer, da polémica questão da liberdade da mulher em relação ao seu próprio corpo. De uma forma ou de outra, sabe-se que o aborto é praticada no Brasil: nas populações carentes ou abastadas, em meio a boas condições de higiene ou não, entre mulheres jovens ou maduras. Até que ponto não estaríamos funcionando apenas como mero observadores de uma escalada que pode trazer conseqüências graves para a vida afetiva, biopsíquica e social de uma população feminina que vem sendo engrossada dia após dia?

\section{O ABORTO COMO PRÁTICA SOCIAL E QUESTÃO DE SAUDE}

Ao analisarmos a questão do aborto no Brasil de hoje não devemos nos desvincular de todo o conhecimento que se tem sobre o assunto em termos mundiais. Embora não seja possível abarcar todas as nuances que o tema comporta, vamos nos deter aqui nos principais trabalhos realizados a partir de 1960, com o objetivo de verificar como a questão do aborto vem sendo tratada ao longo dessas décadas.

A partir da tese de LIMAR, um marco nas pesquisas junto a escolas médicas, foi mostrada a incidência do aborto como responsável por inúmeras mortes hospitalares. Assim, esta prática - e suas conseqüências - eram vistas como problemas de saúde pública, requerend atenção médica especial, além de propiciar a ocupação a alto custo, de leitos hospitalares.

Para CANESQUI^ó, que analisou a constituição dá política de planejamento familiar no Brasil, o aborta constituía um problema universal, que afetava a saúd $\wedge$ l pública e provocava a desintegrarão da família gerando problemas de diferentes ordens à mulher.

Várias vezes, em pesquisas realizadas em nossa pais, o aborto foi associado a crime e doença, transfor mando-se num problema médico-social que incidi, principalmente na faixa de mulheres entre 25 e 29 anos

As principais causas desse estado de coisas estarias relacionadas, segundo uma gama variada de análises com o atraso cultural, a falta de educação sexual, a pa ternidade "irresponsável” e a ignorância do uso d, métodos anticoncepcionais.

Pelos diferentes aspectos que encerra sabese hoj que somente a atenção médica não reduz a ocorrênci dessa prática social do aborto provocado, uma vez qu vários fatores estão presentes na sua ocorrência e $\mathrm{n}^{\wedge} \mathrm{l}$ processo de atendimento à questão. Como saída gera mais relevante e mais eficaz, estaria a colocação er prática de uma efetiva política de planejamento família ou reprodutivo onde a mulher, vista na sua totalidade lançaria novos elementos à análise do problema.

Para HUTCHINSON ${ }^{12}$, o aborto está situado entr os vários tabus que podem povoar uma sociedade, cons tituindo motivo de vergonha em alguns meios, sobretud entre as classes mais altas. Entretanto, para ele, a prátic do aborto como método limitador da família não é exclu siva de nenhum grupo económico ou social.

Em relação à magnitude do problema como questão de saúde pública NAKAMURA \& BARRETO $^{18}$, citar que, entre 2800 mulheres entrevistadas, $15 \%$ delas játive ram histórico de aborto espontâneo ou provocado. Alén disso, constataram que a incidência do aborto é predomi nantemente maior nas áreas urbanas, numa proporção 2: em relação às áreas rurais, conforme os dados seguintes:

\begin{tabular}{lr}
\hline São Paulo (município) & $15 \%$ \\
Outras áreas urbanas & $13,5 \%$ \\
Areas rurais & $7 \%$ \\
\hline
\end{tabular}

Corroborando esses dados FARIAS9 revela que en tre 1697 mulheres pesquisadas no decorrer de 3 meses num hospital de Salvador, $21 \%$ registraram complicaçõe pós-aborto. Também RICE-WRAY ${ }^{22}$ cita que para cad 1000 partas encontrou 233 mulheres tratadas por com- 
plicações pós-aborto. Vale destaque a pesquisa realizada por NEME et aló, abrangendo.o período 19441962, cujos dados demonstram que das 5500 complicações de gravidez ou parto, um terço estava relacionado com complicações pós-aborto.

Em termos de Brasil calcula-se, na atualidade, que sejam praticados 2,5 milhões de abortos por ano, o que equivaleria a um total de 6850 abortos por dia, 285 por hora e 5 por minuto. ${ }^{1,20,21}$

Esse valor adquire grande significado para o campo da saúde quando se observa as complicações mais frequentes, tais como: infecção pélvica, hemorragia e choque séptico. Deve-se considerar igualmente que o aborto provocado pode afetar a mulher e as gestações subsequentes (prematuridade, gravidez ectópica, abortamento espontâneo, baixo peso ao nascer). Com a rep etição do número de abortos praticados os riscos acentuam-se, trazendo não só implicações de ordem organica, mas também social, econômica e psíquica.

Entre as consequências de ordem organica, podemos citar até mesmo o risco da infecundidade. Entre os casos de infecção puerperal, sabe-se que $60 \%$ deles são ocasionados por aborto provocado (choque septêmico) ${ }^{19}$

Outro dado marcante diz respeito aos óbitos maternos em 10 cidades latino-americanas: $34 \%$ das mortes são provocados por aborto. No Chile, por exemplo, a taxa percentual varia de $30 \%$ a $41 \%$ no que diz respeito aos óbitos maternos registrados. ${ }^{1,7,18,20,25}$

Do ponto de vista social a prática do aborto está relacionada, além de processos gerais, com uma série de processos particulares que vão desde as dificuldades de sobrevivência da mulher ou da família em meio a uma urbanização desenfreada, à carência de programas educativos e de planejamento reprodutivo, à alta do custo de vida, além de outros. Neles residem as possibilidades da mulher procurar o aborto como meio de terminar uma gravidez indesejada ou "impossível" de ser levada a cabo pela precariedade de sua situação pessoal ou de condição de vida.

A questão do aborto entre as adolescentes constitui um capítulo à parte no universo relacionado a essa prática. E falo que hoje em dia as adolescentes apresentam um início de vida sexual mais precoce. Num país desenvolvido como os Estados Unidos sabe-se que 50\% das jovens são sexualmente ativas e que destas, $50 \%$ não usam métodos contraceptivos. Na Inglaterra e País de Gales (1978), cerca de 3\% do total de abortos praticados referemse a jovens menores de 16 anos, e destas, 50\% procuraram os serviços públicos^$\wedge 23$. O que dizer, então, de um país como o Brasil, marcado pelo analfabetismo e pela falta de informação na área?

\section{UM ACOMPANHAMENTO HISTÓRICO DA QUESTÃO}

Num país em que não raras vezes crimes de pequeno, médio ou grande porte deixam de ser julgados e, consequentemente, punidos - pela concorrência dos mais diversos fatores, tais como, falta de provas, ineficiência dos sistemas policiais e/ou jurídicos, interesses “ocultos”, não haverá de ser diferente em relação à prática do aborto, considerada ilegal pelo atual Código Penal, em vigor desde 1940. Segundo Decreto-Lei n 2848 , de 7 de dezembro de 1940 (artigos 124 a 127), somente duas modalidades de aborto não são puníveis: o aborto terapêutico - feito como tentativa de salvar a vida da gestante - e o aborto sentimental - decorrente de gravidez por estupros. ${ }^{8,10,11}$

Ainda que no Brasil, o aborto, essa prática clandestina por excelência, carregue a marca da reprovação, certamente não terá sido assim no decorrer da história da humanidade. Sabe-se que desde os povos da antiguidade este era difundido entre a maioria das culturas pesquisadas. O imperador chinês Shen Nung cita em texto médico escrito entre 2737 e 2696 a.C. a receita de um abortífero oral, provavelmente contendo mercúrio.

Na antiga Grécia, o aborto era preconizado por Aristóteles como método eficaz para limitar os nascimentos e manter estáveis as populações das cidades gregas. Por sua vez, Platão opinava que o aborto deveria ser obrigatório, por motivos eugénicos, para as mulheres com mais de 40 anos e para preservar a pureza da raça dos guerreiros. Sócrates aconselhava às porteiras, por sinal profissão de sua mãe, que facilitassem o aborto às mulheres que assim o desejassem $\sim^{\circ}$. Já Hipócrates, em seu juramento, assumiu o compromisso de não aplicar pressário em mulheres para provocar abortou.

Entre os Gauleses, o aborto era considerado um direito natural do pai, que era o chefe incontestável da família, com livre arbítrio sobre a vida ou a morte de seus filhos, nascidos ou não nascidos. ${ }^{10} \mathrm{O}$ mesmo ocorria em Roma, onde o aborto era uma prática comum, embora interpretada sob diferentes ópticas, dependendo da época. Quando a natalidade era alta, como nos primeiros tempos da República, ela era bem tolerada. Com-o declínio da taxa de natalidade a partir do Império, a legislação tornou-se extremamente severa, caracterizando o aborto provocado como delito contra a segurança do Estado. ${ }^{5}$

O livro do Exodo cita que, dentre os povos hebreus, era multado aquele homem que ferisse mulher grávida, fazendo-a abortar. Esse ato de violência obrigava aquele que ferisse a mulher a pagar uma multa ao marido desta, diante dos juizes; se, porém, a mulher viesse a morrer em consequência dos ferimentos recebidos aplicava-se ao culpado a pena de morte. 
Ainda que a regra geral se voltasse para a severidade legal, que punia a mulher com o exílio ou com castigos corporais extremados, na prática imperava quase sempre a impunidade. Com o advento do Cristianismo, entretanto, o aborto passou a ser definitivamente condenado, com base no mandamento "Não Matarás". Essa posição é mantida até hoje pela Igreja Católica mas, ao contrário do que se possa pensar, ela não foi tão uniforme ao longo dos anos. Interesses políticos e económicos contribuíram para que isso acontecesse.

São Tomás de Aquino, com sua tese da animação tardia do feto, contribuiu para que a posição da Igreja com relação à questão fosse mais benévola do que nos dias de hoje. ${ }^{11}$

No Século XIX, o aborto expandiu-se consideravelmente entre as classes mais populares, em função do êxodo crescente do campo para a cidade e da deterioração de seu nível de vida. Isso certamente constituía uma ameaça para a classe dominante já que representava um decréscimo na oferta de mão-de-obra barata, tão necessária para a expansão das indústrias. Na classe alta o controle da natalidade era obtida através de uma forte repressão sexual sobre seus próprios membros e a prática do aborto, embora comum, era severamente condenada. 5,10

Hoje em dia torna-se mais e mais comum que o número de defensores da prática livre do aborto venha crescendo respaldados em razões de ordem económica, política, social e demográfica muito embora, em função de contextos históricos, a questão possa apresentar-se controvérsa e ambígua.

Alguns acontecimentos históricos, no início deste século, ocasionaram certas modificações importantes nas legislações que regiam a questão do aborto e são explicitadoras dessas diferentes ordens de motivos que fundamentam concepções e políticas a respeito.

Com a Resolução de 1917, na União Soviética, o aborto deixou de ser considerado um crime naquele país, tornando-se um direito da mulher a partir de decreto de 1920. Processo inverso aconteceu em alguns países da Europa Ocidental, sobretudo aqueles que sofreram grandes baixas durante a Primeira Guerra Mundial, que optaram por uma política natalista, com o endurecimento na legislação do aborto. Como exemplo, podemos citar a França, que introduziu uma lei particularmente severa no que diz respeito não só à questão do aborto, mas também quanto aos métodos anticoncepcionais. .0,21 $^{10}$

Com a ascensão do nazifacismo, as leis antiabortivas tornaram-se severíssimas nos países em que ele se instalou, com o lema de se criarem "filhos para a pátria". O aborto passou a ser punido com a pena de morte, tornando-se crime contra a nação, a exemplo do que ocorreu em certo momento no Império Romano.
Após a Segunda Guerra Mundial, as leis continuaram bastante restritivas até a década de 60 , com exceção dos países socialistas, dos países escandinavos e do Japão (país que apresenta lei favorável ao aborto desde 1948, ainda na época da ocupação americana), ${ }^{10,21,26}$

A partir dos anos 60, em virtude da evolução dos costumes sexuais, da nova posição da mulher na sociedade moderna e de outros interesses de ordem político-econômica, a tendência foi para uma crescente liberalizarão. Acentuou-se na década de 70 e as estatísticas revelam que, em 1976, 2/3 da população mundial já viviam em países que apresentaram as leis mais liberais, mais da metade delas foi aprovada nesta última década.

Mas, há também casos de países que voltaram às leis anteriores, como aconteceu com a Romênia, Bulgária e Hungria (razões de ordem demográfica) e com Israel (motivos político-religiosos).

Se fôssemos traçar um quadro indicador das relações entre os diversos países do mundo e o tratamento dado à questão do aborto, teríamos. ${ }^{10,11,15,21}$

\begin{tabular}{lc}
\hline o aborto é realizado por meio de simples solicitação & $35 \%$ \\
o aborto é realizado por razões de ordem social & $24 \%$ \\
$\begin{array}{l}\text { a aborto é realizado por razões de ordem médica, } \\
\text { eugênica ou humanitária }\end{array}$ & $20 \%$ \\
o aborto é realizado para salvar a vida da mãe & $13 \%$ \\
o aborto é totalmente proibido & $4 \%$ \\
situação desconhecida & $4 \%$
\end{tabular}

As situações apresentadas por TIETZE ${ }^{27} \mathrm{e}$ BARRON $^{4}$ não diferem muito do que se observou no quadro acima.

\section{ASPECTOS JURIDICOS}

O Código Penal, que atualmente vigora em nosso país, data de 1940 e é o terceiro existente no Brasil. Os dois primeiros, de 1830 e 1890 , eram bem mais rigorosos que o atual, não prevendo a exceção do aborto para salvar a vida da mãe ou em caso de gravidez decorrente de estupro, conforme se tem hoje. Segundo o Código Penal hoje em vigor, estas duas modalidades de aborto previstas por lei só podem ser praticadas por médicos; o auto-abor- 
to é punido, teoricamente, da mesma forma que o praticado por terceiros, sendo menor a pena para o primeiro (detenção de 1 a 3 anos, de acordo com o artigo 124).

Quanto ao aborto provocado por terceiros, as penas diferem quando há consentimento da gestante, sendo a pena de reclusão de 1 a 4 anos no primeiro caso e de 3 a 10 anos no segundo. Em caso de haver lesões corporais graves na gestante, ou mesmo sua morte, as penas podem ser aumentadas de um terço, ou duplicadas.

Continuam proibidos em nossa legislação os casos de aborto por incesto ou eugénico.

\section{ASPECTOS DAÉTICA MÉDICA}

O Código de Ética Medica foi elaborado pelo Conselho Federal de Medicina, em cumprimento ao artigo 30 da Lei $n^{\circ} 3.268 / 57$ e publicado em 11 de Janeiro de $1965^{\circ}$.

$\mathrm{O}$ artigo 54 do Código de Ética impõe ao médico que não provoque aborto, salvo exceções referidas no artigo 128 do Código Penalize. Para realização do aborto, nestes casos, o médico deverá primeiramente consultar em conferência dois colegas, lavrando a seguir uma ata em três vias. Uma será enviada ao Conselho Regional de Medicina (CRM); outra, ao diretor clínico do estabelecimento onde será guardada pelo médico ao qual foi confiada a internação.

O Código de Processo Etico-Profissional para os conselhos de medicina estabelece no capítulo III, referente às penalidades, mais especificamente em seu artigo 60, que as penas disciplinares aplicáveis pelos conselhos regionais a seus membros podem ser de diferentes graus:

- advertência confidencial em artigo reservado; - censura confidencial em aviso reservado; - suspensão do exercício profissional até 30 dias,

- cassação do exercício profissional “ad referendum” do Conselho Federal.

\section{ASPECTOS RELIGIOSOS}

\section{Catolicismo}

Baseadas no mandamento "Não matarás”, as diversas religiões cristãs condenam a prática do aborto, ainda que a interrupção da gravidez se dê por razões de ordem terapêutica ou sentimental. Em fins do século passado interrompeuse a discussão em torno da animação tardia do feto e atualmente a Igreja apresenta restrições quanto à prática do aborto terapêutico como caminho para se salvar a vida da mãe. Ou seja, condena todo tratamento que vier atentar diretamente contra a vida do feto, embora não condene conseqüências indiretas - a morte do feto, por exemplo - que este tipo de encaminhamento possa ter causado. ${ }^{11,16}$

\section{Igrejas protestantes}

A postura das igrejas protestantes em geral (batista, luterana, metodista, presbiteriana, episcopal e unitária) parece ser um pouco menos rígida que a da igreja católica, uma vez que admite o aborto terapêutico, embora jamais encare o aborto como método de controle da natalidade. De qualquer forma, dá-se grande importancia à vida da mãe, devendo a questão ser resolvida entre médico, pastor e paciente.

De acordo com LADER ${ }^{13}$, os unitáriosuniversalistas foram aquela facção da igreja protestante que mais ousou em relação à questão: em 1963 já defendia a legislação do aborto em caso de perigo físico ou mental para a mãe, gravidez resultante de estupro ou incesto, defeito físico ou mental da criança que está para nascer ou quando existirem (o que abre a possibilidade de solução para vários casos individuais).

\section{Igreja judáica}

O judaísmo tem apresentado uma postura mais flexível no que diz respeito à questão do aborto, provavelmente por apresentar concepções teológicas diferentes em relação à alma e ao "pecado original". Para os judeus, o feto só se transforma em ser humano quando nasce e em pessoa um mês após o nascimento. Além disso, o falo de não existir uma autoridade máxima ditando todas as regras de contada faz com que os judeus possam ter liberdade sobre sua própria consciência. ${ }^{11,16}$

\section{O ABORTO COMO QUESTÃO EM ABERTO: A URGÊECIA DA DISCUSSÃO NA SOCIEDA- DE BRASILEIRA}

Diante dessa gama variada de aspectos que envolvem não somente questões de natureza ética, política e religiosa, por um lado, mas também sócio-econômicas, psicológicas e, sobretudo, de saúde pública, por outro, é que o aborto colocase como problema cuja existência concreta não pode ser ignorada na atualidade exigindo uma ampla discussão pela sociedade brasileira. 
Tal discussão deverá oferecer diretrizes gerais ao estabelecimento de uma política social e de saúde para o selar que contemple, não somente, as implicações dessa prática em termos concretos, mas também, as questões de natureza

\section{BIBLIOGRAFIA}

1. Aborto: crime ou direito? Med Cult. Cient., (2) out/dez, 1983.

2. ALTON, I. R. Nutricional services for pregnant adolescents withim a public high school. $J$. Amer. Diet. Ass., 74 (6):667-9, 1979.

3. AMIRIKIA, H. Contraception for adolescente. The Hagne, Netherlands, Martinus Nighott, 1980.

4. BARRON, L. A. H. Obstetrícia prática. Rio de laneiro, Ed. Científica, 3’Ed., 1952.

5. CABANELLAS, G. El aborto, un problema social, médico y juridico. Buenos Aires, Ed. Atalaya, 1945.

6 CANESQUI, M. A. Notas sobre a constituição poluira de planejamento familiar no Brasil. Vitória, ABEP, 1982 p. 1966-77.

7. CIARI, Jr. C.; ALMEIDA, P. A. M. Análise do coeficiente de mortalidade materna no município de Osasco-SR Rev. Saúde Públ., 6: 237-44, 1972.

8. CONSELHO FEDERAL DE MEDICINA. Código de ética médica. Diário Oficial da União, Rio de Janeiro, 11 jan. 1965.

9. FARIAS, E. E. Condicionantes sócio-econômicos do abortamento provocado. Rev. Paul. Hosp., 20 (2): 25-31, 1972.

10. FRENTE DE MULHERES FEMINISTAS. $O$ que é o aborto? São Paulo, Ed. Cortez, 1980.

11. HOJDA, J. M. Aborto: Liberação ou restrição. São Paulo, 1979. [Dissertação de Mestrado Faculdade de Direito da USP].

12.HUTCHINSON, B. Induced abortion in brazilian married women. Amer Lat., 7 (4): 2133, 1964.

13. LADER, L. Abortion. Indianópolis, BobhsMerril, 1966.

14. LIMA, R. Aborto provocado. Rio de Janeiro, Ed. Refrigeracão, 1965. Rev. Bras. Cresc. Des. Hum., S. Paulo, lV(2), 1994

15. MHANGO, G. G.; GRECH, E. S. Family planning programme and abortion laws in Zambia. Chestment Hill, Mass. Pattfunder Fund, 1979 p. 44-56. ético-jurídicas que perrr^ltarn ao campo da saúde implementar, de falo, uma política de assistência capaz de atender as necessidades da Saúde Reprodutiva da Mulher de modo integral e desmistificada.

16. MILANESI, M. L. Aborto Provocado: estudo retrospectivo em mulheres não solteiras de 15 a 49 anos residentes no Disttito de São Paulo, em 1965. São Paulo, 1968. [Tese de Doutoramento - Faculdade de Saúde PúblicaUSP].

17. MONREAL, T. Factores determinantes de la tendência dei horto ilegal en Chile. Bol. Ofic. Sanit. Panamer., 86 (3): 206-16, 1979.

18. NAKAMURA, M. S.; BARRETO, F. J. de R São Paulo State contraceptiva prevalence survey, PESMI/PUCC 178, final report. Campinas, Pontifical Catholic University of Campinas, 1979.

19. NEME, B. et al. Obituário materno no abortamento criminoso. Am. Bras. Ginec., 59 (1): 7-10, 1975.

20.PANDOLFI, R A.; FACCIOLI, E. Planificação familiar num bairro de Porto Alegre. $J$. Bras. Cinec., 70 (5): 273-82,1970.

21. POPULATION REPORTS. Série E Baltimore, (7) May, 1981

22. RICE-WRAY, E. The provoked abortion a major public health problem. Amer. J. Publ. Hlth, 54(2): 313-21, 1964.

23.SCHOR, N. Aborto como questão de saúde pública: estudo da demanda de mulheres que recorreram ao hospital por complicações do aborto. São Paulo, 1985. [Tese de Doutorado Faculdade de Saúde Pública da USP].

24. SIQUEIRA, A. A. F. de, et ai. Mortalidade materna no Brasil, 1980. Rev. Saúde. Públ., 18(ó), 1984.

25. SOUZA, M. L. de. Mortalidade materna em Florianópolis - Santa Catarina, 1975 a 1979 obituário hospitalar. Santa Catarina, 1982. [Tese de Doutorado - Faculdade de Saúde Pública da USP].

26. TIE1ZE, C. Induced abortion. 3rd. ed. New York, Population Council, 1979 (a Population Council Fact Book).

27. TIEIZE, C. Induced abortion. $4 \wedge^{\wedge} \mathrm{r}^{\wedge} \mathrm{d}$. New York, Population Council, 1981.

recebido em: 01/03/95 aprovado em: 01/04/95 